\title{
PSICOLOGIA E TRABALHO: 0 ESTADO DA ARTE E CONTRIBUIÇÕES PARA AS ORGANIZAÇÕES
}

\author{
Eros E. S. Nogueira \\ Professor da Universidade Federal do Paraná e doutorando em Administração de Empresas na FGV-EAESP. \\ E-mail: Eros@gumail.br
}

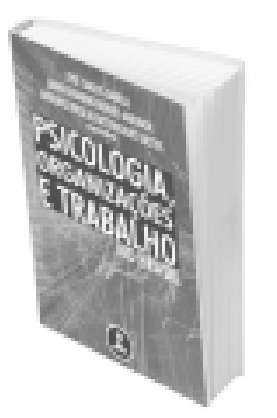

PSICOLOGIA, ORGANIZAÇÕES E TRABALHO NO BRASIL

De José Carlos Zanelli, Jairo Eduardo Borges-Andrade e Antonio

Virgílio Bittencourt Bastos (organizadores).

Porto Alegre: Artmed, 2004. 520 p.
Esta é uma obra dedicada a analisar e conhecer a interface entre a Psicologia e as outras disciplinas vinculadas às organizações e ao trabalho. Além da qualidade de seu conteúdo, diferencia-se de outras similares especialmente pelo fato de os autores a terem orientado para apresentar uma visão do estado atual e dos desafios contemporâneos desse campo do conhecimento e, ainda, a terem ilustrado com a mais recente produção científica desenvolvida no contexto brasileiro. Sua abrangência, entretanto, permite que seja situada também nos campos do comportamento organizacional e da gestão de pessoas e relações de trabalho.

A obra aborda os mais importantes tópicos dessa interface (e.g. motivação, cognição, emoção, afeto, aprendizagem e bem-estar no trabalho em organizações, socialização, poder, cultura e diversidade) e tece, de forma gradual e crescente, uma rede de conceitos que permite relacionar aspectos teóricos e práticos de gestão de pessoas, psicologia do trabal ho epsicologia organizacional. Apresenta uma visão multidisciplinar para se analisarem e diferenciarem os vínculos do indivíduo e dos grupos com a organização e 0 trabalho, assim como para se avaliar a interdependência existente entre eles e seus efeitos.

Os autores pretendem com o livro oferecer uma sólida fundamentação, que possa servir de referência aos pesquisadores e profissionais dessas áreas em suas práticas de diagnóstico, prognóstico, aconsel hamento e intervenção. De fato, a realidade contemporânea das organizações justifica a centralidade dos temas - indicados a seguir - e o esmaecimento da aparente intransponibilidade da fronteira entre os estudos acadêmicos e os domínios gerenciais. Demonstrase a possibilidade de se desenvolver competência e habilidade para lidar com as tensões existentes na dinâmica organizacional, tais como as expressas pelas pressões entre a busca de resultado, agilidade e prontidão a curto prazo, e as necessidades de se al cançarem e manterem os resultados, a cooperação, a integração e a coordenação a longo prazo.

Outro objetivo da obra, segundo os organizadores, reside na possibilidade de seu uso no ensino de graduação e pós-graduação. Para alcançar esses propósitos, extraem da produção científica contemporânea, inclusive contemplando a realidade nacional, um texto e material atualizadose voltados às finalidades profissionais, didáticas e de apoio à pesquisa. 0 livro, que contém 16 capítulos, é ordenado em quatro grandes partes: 0 contexto; o indivíduo no contexto; os processos organizacionais; e a atuação profissional e a produção de conhecimento.

$\mathrm{N}$ a primeira parte, os autores analisam a construção do sentido ocidental de trabalho, sua relação com os modelos modernos de organização do trabaIho, as tendências e desafios atuais. A obra avança no tema ao apreciar o conceito e as principais perspectivas dos 
estudos organizacionais. Analisa, ainda, a estrutura das organizações, seu ambiente, sua ação estratégica, seus processos de ordenação e coordenação, e suas principais tipologias - pré-burocráticas, burocráticas e pós-burocráticas - , com especial ênfase nas abordagens contingencialista, institucionalista e cultural ista.

$\mathrm{N}$ a segunda parte, a atenção se volta para a relação entre o indivíduo e o atual contexto do trabal ho, focalizando os processos psicológicos. Numa minuciosa apreciação da motivação, da cognição e das emoções, afetos e atitudes, é traçado um panorama comparativo dos aportes teóricos e conceituais, e as contribuições dos estudos científicos desses temas e suas possíveis inter-relações. A apresentação que os autores fazem das principais teorias, suas características e limitações, permite ao leitor obter uma visão ao mesmo tempo comparativa e integrada. Pela síntese que a obra realiza, acaba por se constituir em trabalho pioneiro, especialmente com relação à temática sobre os processos cognitivos e das emoções. Ela consegue, com clareza, colocar em discussão a possibilidade de os sujeitos serem atores ativos na reconstrução social da realidade e estabelecer 0 vínculo para que os modelos de gestão contemporâneos possam reconhecer e lidar com esses aspectos. Avalia-se a organização como um lócus onde, simultaneamente, são reunidas a singularidade e a diversidade dos indivíduos, e a contínua reformulação dos significados, valores, emoções e atitudes compartilhados.

Ainda nessa parte há uma cuidadosa avaliação dos conceitos, teorias e modelos que tratam do desenvolvimento, da aprendizagem e da formação de competências sob a ótica da Psicologia, inclusive aspectos quanto à sua aplicação e experimentação. Os autores consideram que os conheci- mentos da Psicologia não podem somente se voltar para o desempenho, devendo proporcionar possibilidades à realização de um maior bem-estar para todos os que se relacionam no ambiente de trabalho. Eles se debruçam, então, sobre a relação do trabaIho com o bem-estar e a saúde mental, investigando, em particular, o sentido e as condições do sofrimento psíquico. Elegem três grandes abordagens: 0 estresse, a psicodinâmica do trabalho, e a epidemiologia do trabalho. Descrevem a formação e o desenvolvimento dessa área de estudo e intervenção, suas relações com outras áreas e disciplinas afins e atuantes no mesmo espaço social, suas principais contribuições teóricas e práticas, e suas limitações. Concluem esta parte estabelecendo um quadro abrangente do que a Psicologia, a Filosofia e a Sociologia vêm proporcionando para se entender por que e como os indivíduos se organizam, interagem etrabal ham uns com os outros. De fato, esta parte da obra oferece condições tanto para uma meIhor compreensão desses processos psicológicos quanto para uma intervenção profissional mais eficientenos contextos organizacionais.

Na terceira parte, o cen tro das atenções está nos processos que local izam os indivíduos nas tarefas voltadas aos objetivos organizacionais. Os autores desenvolvem a conceituação de equipes, propondo não apenas os elementos diferenciadores para a conceituação de grupos de trabalho, mas também seus tipos, etapas e importância para o bom desempenho e o bem-estar. À análise dos processos de socialização e de formação e manutenção das unidades sociais, adicionam a apreciação - a nosso ver indispensável - dos fenômenos sociais do poder, da cultura e da diversidade.

A última parte da obra analisa a atuação profissional e a produção do conhecimento no âmbito da Psicolo- gia Organizacional e do Trabalho. A reflexão inclui uma síntese da trajetória histórica, da configuração atual da área - tanto como campo de conhecimento quanto como espaço de exercício profissional -, e suas tendências e desafios. Os autores, ao focalizarem mais especificamente as questões da produção do conhecimento, demonstram as razões para a crescente importância da área e identificam seu objeto, seus elementos essenciais, requisitos para inserção científica e principais centros de onde se articulam as pesquisas e publicações especializadas no Brasil.

Antes da publicação da obra, os autores a submeteram a um rigoroso e amplo teste, em cursos de Psicologia e Administração, para avaliar na prática 0 atendimento dos objetivos que justificaram a sua elaboração e publicação. Podemos compreender esses cuidados ao constatarmos que os organizadores, os autores e os co-autores são pesquisadores, professores e profissionais dedicados integralmente à área, com extensa e reconhecida produção nacional e internacional, e intensa participação acadêmica.

É indiscutível o seu valor como revisão esíntese do conhecimento dos temas. Esse valor cresce ainda mais pelo fato de o livro trazer uma apreciação da recente produção acadêmica nacional, e por ter perseguido e obtido a qualidade didática necessária para prestar um serviço de grande utilidade a profissionais, professores e estudantes.

Parte da limitação da obra reside possivelmente nesse seu didatismo. É considerável sua abrangência e sua extensão. Por isso, torna-se obrigatória a síntese, o que - apesar do esmero em não sacrificar o essencial - acaba por convidar os leitores com maior interesse acadêmico a buscar as leituras e a bibliografia usadas e indicadas. 